\title{
Comparison of hematological parameters, iron levels, and oxidative stress in women with and without breast cancer: A case- control study
}

\author{
Afsaneh Rajizadeh ${ }^{1,2}$, Hassan Mozaffari-Khosravi ${ }^{2,} 3^{*}$, Javad Zavar-reza ${ }^{4}$, Seyyed Mostafa Shiryazdi ${ }^{5}$ \\ Received: 23 Dec 2016 \\ Published: 20 Dec 2017
}

\begin{abstract}
Background: Iron is one of the nutrients that has recently received considerable attention because of its dual role in the incidence of breast cancer. The present study aimed at comparing hematological parameters, iron levels, and oxidative stress in women with and without breast cancer.

Methods: The participants in this case-control study were 55 women, of whom 26 were new cases of breast cancer (confirmed by biopsy) as the case, and 29 without cancer (confirmed by mammography) as the control group. All participants underwent blood testing for complete blood count (CBC (free iron, ferritin, total iron binding capacity) TIBC (2, 2-diphenyl-1-picrylhydrazyl (DPPH), and Malondialdehyde (MDA).

Results: The mean \pm SD age of the participants was $44.25 \pm 9.82$ years, and there was no significant difference between groups. Also, no statistically significant difference was found between the 2 groups in variables, except the mean corpuscular volume of red cells $(\mathrm{MCV})$, mean corpuscular hemoglobin concentration (MCHC), and mean cell hemoglobin $(\mathrm{MCH})$. The use of iron supplements was significantly higher in the control than in the case group $(\mathrm{p}=0.01)$, with an odds ratio of $0.19 \%(95 \% \mathrm{CI}: 0.45-0.7)$. The mean serum DPPH was significantly higher in the control than in the case group $(\mathrm{p}=0.006)$, but comparison of serum MDA showed no significant difference between the 2 groups.

Conclusion: Iron deficiency anemia was greater in patients with breast cancer than in those without it. Moreover, iron supplementation appears to have a protective effect against breast cancer incidence. In addition, serum DPPH, as a total antioxidant index, was significantly higher in the control group.
\end{abstract}

Keywords: Iron status, Breast cancer, Oxidative stress, Premenopausal

Copyright $\odot$ Iran University of Medical Sciences

Cite this article as: Rajizadeh A, Mozaffari-Khosravi H, Zavar-reza J, Shiryazdi SM. Comparison of hematological parameters, iron levels, and oxidative stress in women with and without breast cancer: A case- control study. Med J Islam Repub Iran. 2017 (20 Dec);31:114. https://doi.org/10.14196/mjiri.31.114

\section{Introduction}

Breast cancer is the most common form of cancer in women worldwide; 1.1 million new cases of breast cancer are diagnosed annually (1); its prevalence is estimated to be $10 \%$ in the United States, $8 \%$ in Europe, and $1 \%$ in Asia (2); its frequency is significant in Iran at 22 per 1000 population. A serious concern in Iran is that the average age of developing the disease is 10 years earlier than in other countries (3).

Breast cancer is a progressive malignant disease of breast tissue (4), and its warning signs are changes in the

Corresponding author: Dr Hassan Mozaffari-Khosravi, mozaffari.kh@gmail.com

1. Nutrition and Food Security Research Center, Shahid Sadoughi University of Medical Sciences, Yazd, Iran.

2. Department of Nutrition, School of Public Health, Shahid Sadoughi University of Medical Sciences, Yazd, Iran.

3. Yazd Diabetic Research Center, Shahid Sadoughi University of Medical Sciences, Yazd, Iran.

4. Department of Biochemistry, Faculty of Medicine, Shahid Sadoughi University of Medical Sciences, Yazd, Iran

5. Department of General Surgery, Shahid Sadoughi University of Medical Sciences, Yazd, Iran. appearance of the breast including asymmetrical breasts, liquid excretion from the nipple, skin decompression, and a palpable mass in the breast (5). The disease recurs in $30 \%$ of cases, leading to metastasis and malignant forms of cancer (6). It is estimated that annually 458000 million people lose their lives to this disease worldwide (7). As breast cancer is one of the most expensive cancers to treat (3), its treatment imposes heavy costs on patients and the government (8). Breast cancer is a multifactorial disease (9). Studies show that the presence of genetic and heredi-

$\uparrow$ What is "already known" in this topic:

Iron is one of the nutrients that has recently received considerable attention because of its dual role in the incidence of breast cancer.

$\rightarrow$ What this article adds:

Iron negative balance is more common in patients with breast cancer than in those without it, and iron supplementation can be useful for these cancer patients. 
tary mutations in breast genes BRCA1/BRCA2 is found in only $5 \%$ to $10 \%$ of cases (5). Environmental factors, such as age, infertility, age at first pregnancy, age at menopause, and use of hormones (estrogen or progesterone) after menopause, play greater roles in development of the disease (9). Although estrogen has a better-known role in the pathogenesis of breast cancer (10), the effect of nutrition on the incidence of the disease has also been considered in recent years (11).

Research has shown that diet affects tumor growth by altering the metabolism of cancer cells in the latency period (12). Various studies have assessed the effect of micronutrients and minerals on the incidence of and improvements in breast cancer (13-15), among which the role of iron in the pathogenesis of breast cancer is still controversial (16).

Iron is a trace element that plays a vital role in the human body (17). The most important function of this element is in the structure of hemoglobin as a carrier of oxygen in the blood (18). In addition, iron acts as a coenzyme to many enzymes and is a structural component of myoglobin (19). Regulation of iron homeostasis in the body is crucial. Iron also acts like a double- edged sword (20): the lack of iron causes iron deficiency anemia, which limits the delivery of oxygen to tissues, and its accumulation causes iron overload, increases oxidative stress, and produces free radicals in the body (21). This also points to a dual role for iron in breast cancer (16).

Because iron overload and iron deficiency are both problematic states (16), it is important to balance this element in the body (21). The prevalence of anemia in Iran is $20 \%$ to $30 \%(22)$, but a number of foods enriched with this element are available (23). This poses the dilemma of whether iron deficiency plays a more important role in the pathogenesis of breast cancer than its overload. Considering the increased incidence of this cancer in Iran and the need for its prevention (24), the present study aimed at comparing hematologic parameters, iron status, and oxidative stress in women with and without breast cancer.

\section{Methods}

\section{Study design and participants}

This case-control analytic study was conducted from May 2014 to May 2015. The volunteer participants were 26 women diagnosed with breast cancer and 29 women, who were confirmed to be free of breast cancer. Inclusion criteria for the case group were as follow: females aged 25 to 65 years, a positive breast tissue biopsy, receiving no interventional treatment, no history of cysts or other cancers, no history of hormone replacement therapy (HRT), and no history of cardiovascular or hepatic disease, diabetes, or thalassemia. Inclusion criteria for the control group were as same as the case group, but without incidence of breast cancer, as confirmed by mammography. Individuals in both groups were frequency-matched by age and the presence or absence of menopause.

At the beginning of the study, this project was approved in the Health College's Research Council of Shahid Sadoughi University of Medical Sciences; then, 4 hospitals in the city of Yazd in Iran (Shahid Sadoughi, Gou- darz, Shahid Rahnemoon, and Seyyed al-Shuhada) were coordinated for sampling. After informed consent was obtained from all participants, blood samples were taken from patients meeting the inclusion criteria with suspected breast cancer before surgical biopsy of breast tissue after they gave consent to participate in the study. The pathology was examined by a physician at 15 days post-biopsy, and the patients with a confirmed diagnosis of breast cancer were included in the case group. The controls were selected from those patients who referred to the mammography section of the same hospital and whose mammography results confirmed no signs of cancer, as assessed by the physician. The patients who met the inclusion criteria were called and invited to provide a blood sample at the laboratory, if they were willing to participate.

\section{Measurements}

Five $\mathrm{mL}$ of fasting venous blood was collected from all participants to measure biochemical parameters. Blood sample was taken at between 7 to 8 AM. Serum samples were produced from blood samples by centrifugation (1500 to $2000 \mathrm{~g}$ ) for 10 minutes and were frozen in microtubes at $-70^{\circ} \mathrm{C}$. After receiving the pathology results, the samples were tested, while preserving the requirements. All tests were performed at Shahid Sadoughi hospital laboratory.

Each participant completed a 24-hour dietary recall questionnaire and provided demographic information. For anthropometric assessment, weight was measured using a Seca digital scale (Germany), with an accuracy of $\pm 100 \mathrm{~g}$ and minimum coverage. The tests performed were $\mathrm{CBC}$, TIBC, ferritin, free iron, total protein, and oxidative stress indices, Malondialdehyde (MDA), and serum 2, 2diphenyl-1-picrylhydrazyl (DPPH). CBC was measured using the Sysmex KX-2 $1^{\text {tm }}$ automated hematology analyzer (Sysmex, Wakinohama kaigandori, Japan), and serum free iron was measured by the photometric method using the Ferrene kit (Biorexfars, Shiraz, Iran). The normal range of serum-free iron for females, according to manufacturer instructions (by age), was 37-149 $\mu \mathrm{g} / \mathrm{dL}$. TIBC was measured by direct method using a kit (ZiestChemDiagnostics, Tehran, Iran), for which the normal range in females was $250-450 \mu \mathrm{g} / \mathrm{dL}$ (by age). Serum total protein was measured by the photometric method using a total protein kit (Pars Azemun, Tehran, Iran), for which the normal range in females (by age) was 6.6-8.8 g/dL. Serum ferritin was measured by direct method using a kit (Acculite Clia Microwells Ferritin Test System, California, USA), for which the normal range for females was 10-126 ng/mL (by age).

DPPH and serum MDA were tested by biochemistry experts in the laboratory in the following manner: The total antioxidant capacity of total plasma TAC, measured by the resuscitation combination of DPPH-1, 1. The $20 \mu \mathrm{L}$ of plasma was added to phosphate buffer at $\mathrm{pH}=7.4$ and then incubated in a methanol solution of DPPH for 30 minutes. The absorbance volume was then read at $517 \mathrm{~nm}$, and the trapped capacity of DPPH was calculated as $\mathrm{DPPH}=(\mathrm{A}-\mathrm{AX}) / \mathrm{A} \times 100$, in which A denotes DPPH absorption with methanol, and AX denotes DPPH absorbed 
with plasma. The TAC measurement was reported based on the percentage of reduction of plasma DPPH (25).

MDA was measured by thiobarbituric acid reaction (TBARs) using the Calorimetry method. Briefly, $0.5 \mathrm{~mL}$ of plasma or standard $3 \mathrm{~mL}$ phosphoric acid with $1 \mathrm{~mL}$ aqueous $0.6 \%$ Barbituric acid (TBA) was placed in a water bath for 45 minutes. After cooling, $4 \mathrm{~mL}$ of n-butanol was added and mixed. The n-butanol phase was separated by centrifugation, and the light absorbance in $523 \mathrm{~nm}$ was read with a spectrophotometer and reported using the MDA standard based on $\mathrm{nmol} / \mathrm{mL}$ plasma (26).

Ethical approval: All procedures performed in studies involving human participants were in accordance with the ethical standards of the institutional and/or national research committee and with the 1964 Helsinki declaration, and its later amendments or comparable ethical standards.

\section{Statistical analysis}

SPSS 16 software was used for data analysis. Student $t$ test was used to compare the means. To compare the frequency distributions of qualitative variables, chi square test was used. A p-value less than 0.05 was considered significant. Odds ratios (ORs) and corresponding 95\% confidence intervals (CIs) were computed. Moreover, N4 software was used to analyze the nutritional data. After data analysis, the participants were divided into 3 groups based on iron measurement indicators: (1) those with normal levels of iron (hemoglobin of 12-16 g/dL and ferritin levels below $150 \mu \mathrm{g} / \mathrm{l})$, (2) those exhibiting iron deficiency anemia (ferritin below $10 \mu \mathrm{g} / \mathrm{l}$ and hemoglobin below $12 \mathrm{~g} / \mathrm{dL}$ ), (3) and those exhibiting iron overload (ferritin above $150 \mu \mathrm{g} / \mathrm{dL}$ ) (28). The values were considered significant at $\mathrm{p}<0.05$.

\section{Results}

Of the 55 participants, $26(47.3 \%)$ were in the case and $29(52.7 \%)$ in the control groups. All participants were married, with a mean $\pm \mathrm{SD}$ age of $44.25 \pm 9.82$ years $(45.92 \pm 11.33$ years in the case group and $42.75 \pm 8.15$ years in the control group), but the difference was not statistically significant $(p=0.10)$. Table 1 demonstrates that mean dietary intake and body weight were not significantly different between the groups; however, mean iron level was higher in the case group than the control group. Table 1 demonstrates the mean daily dietary intake, weight, and some properties of fertility, but no significant difference was observed between any of these variables.

Table 2 compares the mean hematological parameters, iron status, and oxidative stress. Only mean $\mathrm{MCV}$, $\mathrm{MCHC}, \mathrm{MCH}$, and DPPH showed significant differences between groups. Although this difference was not significant for other variables, the hemoglobin and hematocrit levels were less in the case group than in the control group.

Table 1. Comparison of mean $( \pm \mathrm{SD})$ of daily dietary intake, weight and reproductive data between groups

\begin{tabular}{|c|c|c|c|}
\hline Variable & Case group $(n=26)$ & Control group $(n=29)$ & $\mathrm{p}^{*}$ \\
\hline Energy (kcal) & $2445.91 \pm 575.09$ & $2375.29 \pm 525.62$ & 0.65 \\
\hline Protein $(g)$ & $80.86 \pm 18.07$ & $76.42 \pm 27.74$ & 0.51 \\
\hline Carbohydrate (g) & $360.69 \pm 89.50$ & $343.50 \pm 77.81$ & 0.47 \\
\hline Fat $(\mathrm{g})$ & $78.65 \pm 25.58$ & $77.94 \pm 21.85$ & 0.91 \\
\hline $\operatorname{Iron}(\mathrm{mg})$ & $21.47 \pm 9.94$ & $24.49 \pm 8.78$ & 0.25 \\
\hline Vitamin $\mathrm{D}(\mu \mathrm{g})$ & $2.16 \pm 3.62$ & $1.20 \pm 1.38$ & 0.20 \\
\hline Vitamin E(mg) & $2.62 \pm 2.58$ & $3.10 \pm 2.74$ & 0.52 \\
\hline Vitamin $\mathrm{A}(\mathrm{RE})^{* *}$ & $702.42 \pm 387.57$ & $723.91 \pm 366.27$ & 0.84 \\
\hline Weight(kg) & $66.75 \pm 8.54$ & $65.05 \pm 5.29$ & 0.46 \\
\hline Gravida & $4.05 \pm 2.66$ & $3.23 \pm 1.63$ & 0.21 \\
\hline Number of breastfeeding & $3.29 \pm 2.25$ & $2.73 \pm 1.51$ & 0.33 \\
\hline The last lactation (years ago) & $13.11 \pm 10.12$ & $14.57 \pm 9.48$ & 0.63 \\
\hline
\end{tabular}

*: Student t-test, **- $1000 \mu \mathrm{g}$ retinol equivalent

Table 2. Comparison of mean $( \pm \mathrm{SD})$ hematological parameters, iron status and serum oxidative stress between groups

\begin{tabular}{|c|c|c|c|}
\hline Variable & Case group $(n=26)$ & Control group $(n=29)$ & $\mathrm{p}^{*}$ \\
\hline $\mathrm{RBC}^{1}$ & $4.70 \pm 0.70$ & $4.57 . \pm 0.41$ & 0.27 \\
\hline Hemoglobin (g/dL) & $12.23 \pm 1.44$ & $13.06 \pm 1.13$ & 0.38 \\
\hline Hematocrit (\%) & $38.48 \pm 4.13$ & $39.87 \pm 3.24$ & 0.32 \\
\hline $\mathrm{MCV}^{2}(\mathrm{fl})$ & $81.77 \pm 7.57$ & $87.21 \pm 3.88$ & 0.001 \\
\hline $\mathrm{MCH}^{3}(\mathrm{pg})$ & $26.10 \pm 3.59$ & $28.58 \pm 1.99$ & 0.001 \\
\hline $\mathrm{MCHC}^{4}(\mathrm{gr})$ & $31.76 \pm 1.73$ & $32.73 \pm 1.19$ & 0.01 \\
\hline Ferritin $(\mathrm{ng} / \mathrm{mL})$ & $89.87 \pm 87.31$ & $88.13 \pm 106.14$ & 0.92 \\
\hline $\mathrm{TIBC}^{5}(\mu \mathrm{g} / \mathrm{dL})$ & $3.10 \pm 64.92$ & $3.24 \pm 60.51$ & 0.97 \\
\hline Free iron $(\mathrm{mg} / \mathrm{dL})$ & $78.12 \pm 15.58$ & $80.82 \pm 12.61$ & 0.93 \\
\hline Total Protein $(\mathrm{mg} / \mathrm{dL})$ & $7.87 \pm 0.76$ & $7.92 \pm 0.73$ & 0.76 \\
\hline \multicolumn{4}{|l|}{ Oxidative stress markers } \\
\hline $\mathrm{MDA}^{6}(\mu \mathrm{g} / \mathrm{dL})$ & $6.01 \pm 12.52$ & 2. $8 \pm 2.55$ & 0.21 \\
\hline $\mathrm{DPPH}^{7}(\mu \mathrm{g} / \mathrm{dL})$ & $2.73 \pm 0.82$ & $4.84 \pm 3.35$ & 0.006 \\
\hline
\end{tabular}

*: Student t-test

1. Red blood cell coun

Mean corpuscular volume of red cells

Mean cell hemoglobin

4. Mean corpuscular hemoglobin concentration

5. Total iron binding capacity

Serum Malondialdehyde

7. 2, 2-diphenyl-1-picrylhydrazyl 


\begin{tabular}{|c|c|c|c|c|}
\hline Variable & $\begin{array}{c}\text { Case group } \\
(\mathrm{n}=26)\end{array}$ & $\begin{array}{c}\text { Control group } \\
(\mathrm{n}=29)\end{array}$ & $\mathrm{p}^{*}$ & $95 \% \mathrm{CI}(\mathrm{OR})$ \\
\hline \multicolumn{5}{|l|}{$\mathrm{RBC}^{1}$} \\
\hline $\operatorname{low}(4.2<)$ & $2(7.6)^{* *}$ & $0(0) * *$ & 0.12 & $1.64-2.96(2.20)$ \\
\hline Normal(4.2-5.4) & $24(92.4)$ & $29(100)$ & & \\
\hline \multicolumn{5}{|l|}{ Hemoglobin (g/dL) } \\
\hline $\operatorname{Low}(12<)$ & $9(34.6)$ & $7(24.1)$ & 0.55 & $0.51-5.37(1.66)$ \\
\hline Normal(12-16) & $17(65.4)$ & $22(75.9)$ & & \\
\hline \multicolumn{5}{|l|}{ Hematocrit $(\%)$} \\
\hline $\operatorname{Low}(37<)$ & $10(38.4)$ & $7(24.1)$ & 0.38 & $0.61-6.27(1.96)$ \\
\hline Normal(37-47) & $16(61.9)$ & $22(75.9)$ & & \\
\hline \multicolumn{5}{|l|}{$\operatorname{MCV}^{2}(\mathrm{fl})$} \\
\hline $\operatorname{Low}(90<)$ & $6(23.0)$ & $0(0)$ & 0.006 & $1.74-3.43(2.45)$ \\
\hline Normal(80-90) & $20(77.0)$ & $29(100)$ & & \\
\hline \multicolumn{5}{|l|}{$\mathrm{MCH}^{3}(\mathrm{pg})$} \\
\hline $\operatorname{Low}(27<)$ & $13(50.0)$ & $5(17.2)$ & 0.01 & $1.39-16.46(4.8)$ \\
\hline $\operatorname{Normal}(27-31)$ & $13(50.0)$ & $24(82.8)$ & & \\
\hline \multicolumn{5}{|l|}{$\mathrm{MCHC}^{4}(\mathrm{gr})$} \\
\hline $\operatorname{Low}(33<)$ & $5(19.2)$ & $1(3.6)$ & 0.09 & $0.69-59.27(6.4)$ \\
\hline Normal(33-37) & $21(80.8)$ & $27(96.4)$ & & \\
\hline \multicolumn{5}{|l|}{ Ferritin $(\mu \mathrm{g} / \mathrm{dL})$} \\
\hline $\operatorname{Low}(10<)$ & $4(18.2)$ & $2(7.7)$ & 0.39 & $0.43-16.98(2.6)$ \\
\hline Normal(10-126) & $18(81.8)$ & $24(92.3)$ & & \\
\hline \multicolumn{5}{|l|}{$\operatorname{TIBC}^{5}(\mu \mathrm{g} / \mathrm{dL})$} \\
\hline $\operatorname{Low}(250<)$ & $5(20.0)$ & $2(6.9)$ & 0.22 & $0.59-19.2(3.37)$ \\
\hline Normal(250-450) & $20(80.0)$ & $27(93.1)$ & & \\
\hline \multicolumn{5}{|l|}{ Free iron (mg /dL) } \\
\hline $\operatorname{Low}(37<)$ & $3(11.5)$ & $0(0)$ & 0.09 & $1.66-3.0(2.26)$ \\
\hline Normal(37-149) & $23(88.5)$ & $29(100)$ & & \\
\hline \multicolumn{5}{|l|}{ Total Protein (mg /dL) } \\
\hline $\operatorname{Low}(6.6<)$ & $3(13.0)$ & $1(3.7)$ & 0.32 & $0.37-40.36(3.9)$ \\
\hline $\operatorname{Normal}(6.6-8.8)$ & $20(87.0)$ & $26(96.3)$ & & \\
\hline \multicolumn{5}{|l|}{ Cancer history } \\
\hline Yes & $3(11.5)$ & $6(20.6)$ & 0.71 & $0.11-2.24(0.5)$ \\
\hline No & $23(88.5)$ & $23(19.4)$ & & \\
\hline \multicolumn{5}{|c|}{ Iron Supplement (Regularly) } \\
\hline Yes & $4(15.3)$ & $14(48.2)$ & 0.01 & $0.54-0.7(0.19)$ \\
\hline No & $22(84.7)$ & $15(51.8)$ & & \\
\hline \multicolumn{5}{|l|}{ Menopause } \\
\hline Yes & $8(30.7)$ & $9(31.0)$ & 0.6 & $0.31-3.10(0.98)$ \\
\hline No & $18(69.3)$ & $20(69.0)$ & & \\
\hline $\begin{array}{l}\text { *: Chi-Square Tests; **: N } \\
\text { 1. Red blood cell count } \\
\text { 2. Mean corpuscular volum } \\
\text { Mean cell hemoglobin } \\
\text { 4. Mean corpuscular hemog } \\
\text {. Total iron binding capaci }\end{array}$ & & & & \\
\hline
\end{tabular}

Table 3 displays the frequency and odds ratios of the hematological parameters and some variables including cancer history, using iron supplement, and menopause. As observed, $15.3 \%$ of the case group versus $48.2 \%$ of the control group took iron supplement regularly, and the difference was statistically significant between the 2 groups $(\mathrm{p}=0.01)$. Moreover, ORs and 95\% CIs for Iron supplement were $\mathrm{OR}=0.19,95 \% \mathrm{CI}: 0.54-0.7, \mathrm{p}=0.01$. As shown, 7 of the participants $(30.9 \%)$ were postmenopausal, of whom $8(47.1 \%)$ were in the case and $9(52.9 \%)$ in the control group.

Examination of iron status in participants revealed that $17.4 \%$ of the case and $4.2 \%$ of the control group had iron deficiency anemia status. Moreover, $26.1 \%$ and $12.5 \%$ of the participants in the case and control groups had iron overload status, respectively. Furthermore, $56.5 \%$ of the case and $83.3 \%$ of the control group had normal iron status. The result of chi square test showed no significant difference among the 3 groups $(p=0.11)$.

\section{Discussion}

The results showed that the mean iron hematologic parameters, except ferritin, were less in the case group than in the control group. The mean MCV and MCHC were significantly less in the case group than in the control group, indicating microcytic hypochromic anemia, largely caused by iron deficiency (21). This qualitative data cannot be relied upon because of the small sample size, but as observed in Table 3, the percentage of people with mean $\mathrm{MCV}$ and $\mathrm{MCHC}$ values below normal levels were significantly higher in the case group. Iron supplementation was also significantly higher in the control group than in the case group, and supplements had a protective effect in the control group $(\mathrm{CI}=95 \%$; 0.54-0.7; $\mathrm{OR}=0.19)$. The results indicated that the case group showed more serious pathological results in serum iron status than the control group. 
Studies have assessed the association of iron consumption with the occurrence of breast cancer and obtained inconsistent results. Studies by Kabat et al. (27, 28) showed no association between iron supplementation and breast cancer, while a study by Kallianpur et al. found that a high intake of heme iron was associated with an increased risk of developing breast cancer in Chinese women (29) .In their study, despite the fact that there was no difference between groups in iron, its mean level was higher in the control group than the case group.

Other studies evaluated serum levels of iron. Pavithara et al. (30) evaluated serum levels of some ions in patients with breast cancer and found that the serum level of iron was higher in the case group than in the control group. Jian et al. (20) studied mice under controlled conditions and found that iron deficiency in premenopausal females may be associated with poorer tumor prognosis (20).

Table 3 of the present study demonstrates that most participants were below the age of menopause. Researchers have shown that the risk of mortality and the prevalence of malignant breast cancer are higher in premenopausal women. Although the reasons for this are not clear, one possible cause is iron deficiency, as this problem is very common in premenopausal women $(20,31)$. Iron is the cofactor of many enzymes, such as propyl 4-hydroxylase, and inhibits this factor by hydroxylation, which induces hypoxia (HIF-1a). In iron deficiency, the inhibitory factor is removed from HIF-1a, and the increase in this substance stimulates the production of vascular endothelial growth factor (VEGF), which is a strong angiogenesis factor in the body. Studies have shown that overexpression of VEGF cells is directly associated with nonestrogen-dependent tumor progression and that serum VEGF levels indicate a higher risk of recurrence and death due to this cancer in patients in the early stages of breast cancer (16).

Although the number of postmenopausal women was roughly equal between groups in the present study, the mean ferritin level was higher in the case group than in the control group. The reason for this is not clear. After menopause, there is an increased risk of iron retention in women (32), and in some studies, a direct correlation has been reported between high levels of ferritin and breast cancer risk (33). It remains unclear whether the cancer results in an increase in ferritin as an acute phase protein, or whether high levels of this protein causes breast cancer (32). Increased ferritin levels are seen more often in postmenopausal women because of iron overload. Iron overload in the body is a preoxidant and can induce oxidative stress and DNA damage. Iron catalyzes Fenton superoxide and hydrogen peroxide $\left(\mathrm{H}_{2} \mathrm{O}_{2}\right)$ produced by aerobic metabolism through the Haber-Weiss reaction to a hydroxyl radical, a strong oxidizing species. Hydroxyl radicals may affect the lipid peroxidation and DNA mutations $(16,32)$.

The oxidative stress presented in Table 1 shows that the DPPH level (as the total antioxidant capacity index) was significantly higher in the control than in the case group. Although the mean MDA level (as lipid peroxidation) revealed no significant difference between the groups, it was higher in the case group than in the control group. To minimize the effects of therapeutic intervention in this study, blood samples were taken from new cases, but the results emphasize an increase in oxidative stress level markers in the case group compared with the control group.

Oxidative stress is an imbalance between the oxidant and antioxidant reactions that leads to the overexpression of the VEGF gene and the increased metastatic potential of the tumor. The balance between oxidants and antioxidants in the body are controlled by many factors (34, 35). Several studies have assessed the association between phytochemical use and antioxidants and found an inverse association between antioxidant consumption and breast cancer in women (11). Moreover, several studies have also found a significant correlation between serum ferritin level and oxidative stress. Given that a high ferritin level is only one of the factors involved, iron cannot be considered to be the most important factor without measuring other factors in this regard (36).

The present study examined hematologic parameters more extensively than previous studies, while measuring oxidative stress indices. As the selected cases were new cases, the sample size of this study was small, which was a limitation of this study. Thus, it is recommended that future studies be designed with a larger sample size. The scarcity of such studies before the age of menopause and additional factors must be considered when assessing the levels of oxidative stress. In addition, a questionnaire should be designed to assess iron intake from different food sources.

\section{Conclusion}

The results indicated that iron deficiency anemia is greater in patients with breast cancer than in patients without breast cancer and that iron supplementation appears to have a protective effect against breast cancer incidence. In addition, serum DPPH, as a total antioxidant index, was significantly higher in the control group.

\section{Acknowledgment}

We would like to thank Shahid Sadoughi University of Medical Sciences for their continued attention and their financial support of this research. We also extend our thanks to the officials and employees of Shahid Sadoughi, Goudarz, Shahid Rahnemoon, and Sayyid al-Shuhada hospitals in Yazd and also thank all the participants whose close cooperation facilitated the completion of this study.

\section{Funding}

This study was funded by Shahid Sadoughi University of Medical Sciences, Yazd, IR Iran (500€).

\section{Conflict of Interests}

The authors declare that they have no competing interests.

\section{References}

1. Ali AN, Vapiwala N, Guo M, Hwang WT, Harris EE, Solin LJ. The impact of re-excision and residual disease on local recurrence after 
breast conservation treatment for patients with early stage breast cancer. Clin Breast Cancer. 2011;11(6):400-5.

2. Davari M, Yazdanpanah F, Aslani A, Hosseini M, Nazari AR, Mokarian F. The Direct Medical Costs of Breast Cancer in Iran; Analyzing the Patient's Level Data from a Cancer Specific Hospital in Isfahan. Int J Prev Med. 2013;748-54(7).

3. Mousavi SM, Montazeri A, Mohagheghi MA, Jarrahi AM, Harirchi I, Najafi $\mathrm{M}$, et al. Breast cancer in Iran: an epidemiological review. Breast J. 2007;13(4):383-91.

4. Crujeiras A, Cueva J, Vieito M, Curiel T, Lopez-Lopez R, Pollan M, et al. Association of breast cancer and obesity in a homogeneous population from Spain. J Endocrinol Invest. 2012;35(7):681-5.

5. Reza M, Reza M, Mahdiyeh L, Mehdi F, Hamid Z. Evaluation Frequency of Merkel Cell Polyoma, Epstein-Barr and Mouse Mammary Tumor Viruses in Patients with Breast Cancer in Kerman, Southeast of Iran. APJCP. 2014;16(16):7351-7.

6. Gonzalez-Angulo AM, Morales-Vasquez F, Hortobagyi GN. Overview of resistance to systemic therapy in patients with breast cancer. Adv Exp Med Biol. 2007;608(2):1-22.

7. Ferlay J, Shin HR, Bray F, Forman D, Mathers C, Parkin DM. Estimates of worldwide burden of cancer in 2008: Globocan 2008. Int J Cancer. 2010;127(12):2893-917.

8. Barron JJ, Quimbo R, Nikam PT, Amonkar MM. Assessing the economic burden of breast cancer in a US managed care population. Breast Cancer Res TR. 2008;109(2):367-77.

9. Anand P, Kunnumakara AB, Sundaram C, Harikumar KB, Tharakan ST, Lai OS, et al. Cancer is a preventable disease that requires major lifestyle changes. Pharm Res-DordR. 2008;25(9):2097-116.

10. Liu J, Guo H, Mao K, Zhang K, Deng H, Liu Q. Impact of estrogen receptor- $\beta$ expression on breast cancer prognosis: a meta-analysis. Breast Cancer Res TR. 2016;156(1):1-14.

11. Mirzayi BR. Dietary phytochemical index and the risk of breast cancer: a case control study in a population of Iranian women. Asian Pac J Cancer P. 2013;14(5):2747-51

12. Munoz-Pinedo C, El Mjiyad N, Ricci J. Cancer metabolism: current perspectives and future directions. Cell Death Dis. 2012;3(1):1-10.

13. Abulkhair O, Saadeddin A, Makram O, Gasmelseed A, Pasha T, Shehata $\mathrm{H}$, et al. Vitamin D levels and breast cancer characteristics: Findings in patients from Saudi Arabia. J Steroid Biochem. 2015;15(7):1-4.

14. Chen P, Li C, Li X, Li J, Chu R, Wang H. Higher dietary folate intake reduces the breast cancer risk: a systematic review and metaanalysis. Brit J Cancer. 2014;110(9):2327-38.

15. Greenlee H, Hershman DL, Jacobson JS. Use of antioxidant supplements during breast cancer treatment: a comprehensive review. Breast Cancer Res TR. 2009;115(3):437-52.

16. Jian J, Yang Q, Dai J, Eckard J, Axelrod D, Smith J, et al. Effects of iron deficiency and iron overload on angiogenesis and oxidative stress - a potential dual role for iron in breast cancer. Free Radical Bio Med. 2011;50(7):841-7.

17. Shen P, Gong B, Xu F, Luo Y, Zhou B, Wang C, et al. Four trace elements in pregnant women and their relationships with adverse pregnancy outcomes. Eur Rev Med Pharmaco. 2015;19(24):4690-7.

18. Bullock GC, Delehanty LL, Talbot AL, Gonias SL, Tong WH, Rouault TA, et al. Iron control of erythroid development by a novel aconitase-associated regulatory pathway. Blood. 2010;116(1):97-108.

19. Lopez A, Cacoub P, Macdougall IC, Peyrin-Biroulet L. Iron deficiency anaemia. The Lancet. 2015;387(7):907-16.

20. Jian J, Yang Q, Shao Y, Axelrod D, Smith J, Singh B, et al. A link between premenopausal iron deficiency and breast cancer malignancy. BMC Cancer. 2013;13(1):307-16.

21. Lawen A, Lane DJ. Mammalian iron homeostasis in health and disease: uptake, storage, transport, and molecular mechanisms of action. Antioxidants \& redox signaling. 2013;18(18):2473-507.

22. Eftekharzadeh-Mashhadi I, Hedayati-Moghaddam MR, Fathimoghadam F, Bidkhori HR, Shamsian SK. Anemia as a Public Health Issue in Mashhad, Iran: Evidence from the First PopulationBased Study. Acta Medica Iranica. 2015;53(3):186-90.

23. Lotfi DM, Zimmerman S. Flour Fortification in the Islamic Republic of Iran: sustainable route to improved health. 2010.

24. Rafiemanesh H, Rajaei-Behbahani N, Khani Y, Hosseini S, Mohammadian-Hafshejani A, Soltani S, et al. Incidence Trend and Epidemiology of Common Cancers in the Center of Iran. Glob J Health Sci. 2015;8(3): 146-55.
25. Janaszewska A, Bartosz G. Assay of total antioxidant capacity: comparison of four methods as applied to human blood plasma. Scand J Clin Lab Inv. 2002;62(3):231-6.

26. Baskol G, Atmaca H, Tanriverdi F, Baskol M, Kocer D, Bayram F. Oxidative stress and enzymatic antioxidant status in patients with hypothyroidism before and after treatment. Exp Clin Endocr Diab. 2007;115(8):522-6.

27. Kabat GC, Cross AJ, Park Y, Schatzkin A, Hollenbeck AR, Rohan $\mathrm{TE}$, et al. Intakes of dietary iron and heme-iron and risk of postmenopausal breast cancer in the National Institutes of HealthAARP Diet and Health Study. The American journal of clinical nutrition. 2010;92(6):1478-83.

28. Kabat GC, Miller AB, Jain M, Rohan TE. Dietary iron and heme iron intake and risk of breast cancer: a prospective cohort study. Cancer Epidemiology Biomarkers \& Prevention. 2007;16(6):1306-8.

29. Kallianpur AR, Lee SA, Gao YT, Lu W, Zheng Y, Ruan ZX, et al. Dietary animal-derived iron and fat intake and breast cancer risk in the Shanghai Breast Cancer Study. Breast Cancer Res TR. 2008;107(1):123-32.

30. Pavithra V, Sathisha T, Kasturi K, Mallika DS, Amos SJ, Ragunatha S. Serum Levels of Metal Ions in Female Patients with Breast Cancer. J Clin Diagn Res. 2015;9(1):BC25-C7.

31. Shams S, Asheri H, Kianmehr A, Ziaee V, Koochakzadeh L Monajemzadeh M, et al. The prevalence of iron deficiency anaemia in female medical students in Tehran. Singapore Med J. 2010;51(2):10916

32. Kabat GC, Rohan TE. Does excess iron play a role in breast carcinogenesis? An unresolved hypothesis. Cancer Causes Contro. 2007; 18(10):1047-53.

33. Moore AB, Shannon J, Chen C, Lampe JW, Ray RM, Lewis SK, et al. Dietary and stored iron as predictors of breast cancer risk: a nested case-control study in Shanghai.

Int J Cancer. 2009;125(5):1110-7.

34. McCOLL BK, Stacker SA, Achen MG. Molecular regulation of the VEGF family-inducers of angiogenesis and lymphangiogenesis. Apmis. 2004;112(7-8):463-80.

35. Guo $\mathrm{CH}$, Hsia S, Chen PC. Distribution of selenium and oxidative stress in breast tumor-bearing mice. Nutrients. 2013;5(2):594-607.

36. Wang W, Knovich MA, Coffman LG, Torti FM, Torti SV. Serum ferritin: past, present and future. Biochim Biophys Acta 2010;1800(8):760-9. 